\title{
Depressive symptoms, quality of sleep, and disease control in women with asthma
}

\author{
Francineide Lima Campos ${ }^{1}$ • Pedro Felipe Carvalhedo de Bruin ${ }^{2}$. \\ Thisciane Ferreira Pinto ${ }^{1}$. Francisco Girleudo Coutinho da Silva ${ }^{2}$. \\ Eanes Delgado Barros Pereira ${ }^{2} \cdot$ Veralice Meireles Sales de Bruin ${ }^{2}$
}

Received: 12 July 2016 /Revised: 19 September 2016 / Accepted: 11 October 2016 / Published online: 29 October 2016

(C) Springer-Verlag Berlin Heidelberg 2016

\begin{abstract}
Purpose A large number of asthmatic patients, particularly females, present inadequate disease control. Depressive symptoms are reportedly common in asthma and have been related to poor disease control, but the mechanism of this association is still unclear. Poor quality sleep, frequently observed in asthmatics, is also a manifestation of depression and has been related to uncontrolled asthma. This study aimed to investigate the relationship between depressive symptoms, sleep quality, and asthma control.

Methods This was a cross-sectional study of 123 women with previous diagnosis of asthma from a reference center in Fortaleza, Brazil. Depressive symptoms were assessed by the Beck Depression Inventory (BDI); quality of sleep was evaluated by the Pittsburgh Sleep Quality Index (PSQI), daytime sleepiness by the Epworth Sleepiness Scale (ESS), and asthma control by the Asthma Control Test (ACT).

Results Inadequate asthma control $(\mathrm{ACT}<20)$ was found in $94(76.4 \%)$ subjects, depressive symptoms in 92 (74.8\%), poor quality sleep (PSQI $>5$ ) in $99(80.49 \%)$, and excessive daytime sleepiness $(\mathrm{ESS} \geq 10)$ in $34(27.64 \%)$. Depressive symptoms were associated with both poor quality sleep $(R=0.326)$ and inadequate asthma control $(R=-0.299)$. Regression analysis showed that depressive symptoms and
\end{abstract}

Pedro Felipe Carvalhedo de Bruin pedrobruin@gmail.com

1 Faculdade de Farmácia, Odontologia e Enfermagem, Universidade Federal do Ceará, Fortaleza, CE, Brazil

2 Faculdade de Medicina, Universidade Federal do Ceará, Rua Prof. Costa Mendes, 1.608, 4o andar, Fortaleza, CE CEP 60430-140, Brazil sleep quality were independent predictors of the level of asthma control.

Conclusion Asthma control in women is independently associated with depressive symptoms and quality of sleep, suggesting that these patients might benefit from simple measures to promote healthy sleep behavior and sleep hygiene and also that routine screening for depression can be relevant, particularly, in poorly controlled cases.

Keywords Asthma $\cdot$ Depression $\cdot$ Sleep $\cdot$ Disorders of excessive somnolence

\section{Introduction}

Asthma is a common disease affecting all age groups, with prevalence rates ranging from 1 to $18 \%$ in different regions of the world [1]. Although in childhood, asthma is more common in boys, after puberty, it becomes more frequent and more severe in the female gender [2]. Patients with asthma characteristically present variable airflow limitation and respiratory symptoms, including dyspnea, wheezing, chest tightness, and cough, which tend to be more pronounced at night [3].

The level of asthma control, i.e., the extent to which disease manifestations can be observed or reduced as a result of treatment, is an important parameter in clinical evaluation, and its monitoring over time has been recommended to guide adjustments to treatment. Asthma control is known to be influenced by genetic factors; gender; underlying disease process; comorbidities, including obstructive sleep apnea; treatment; and psychosocial factors [1]. Depressive symptoms and asthma control have been reported to be negatively correlated, although the exact nature and implications of this association have not been satisfactorily clarified $[4,5]$. 
Nocturnal worsening of asthma may represent an accentuation of the normal circadian variation in airway caliber. It has been demonstrated that inflammation and airway hyperresponsiveness, key components of the disease, also exhibit a circadian pattern, being more pronounced at night [6]. Poor quality sleep and excessive daytime sleepiness have both been reported in individuals with asthma and may have a negative effect on lung function, daytime performance, and quality of life of these patients [7-10]. It is well recognized that nocturnal exacerbations, which are more common in cases of unsatisfactory control of asthma, lead to sleep fragmentation and poor subjective and objective quality of sleep [11]. However, even in patients who are clinically stable, disrupted sleep is often present [12]. Prospective studies have shown that insomnia and poor quality sleep are risk factors for the initial development of depression as well as for episodes of recurrence [13]. While poor sleep quality could be a vulnerability factor for the later development of depression, it has also been suggested that it could be a marker of subclinical depression [14]. Thus, sleep problems, common in patients with depression and/or asthma, may contribute to a potential vicious circle. Adequate clarification of the relationship between these conditions can be of major importance for the adequate treatment and control of asthma [10].

The main purpose of this study was to investigate the relationship between depressive symptoms, sleep quality, and degree of asthma control.

\section{Methods}

\section{Patients and study design}

This is a cross-sectional, descriptive study of female patients from the asthma outpatient clinic at a reference center in Fortaleza, Brazil. The study sample comprised 123 consecutive women with asthma who attended scheduled appointments, from August 2012 to January 2013. Shift workers, patients presenting significant respiratory discomfort during the interview, and those with severe cognitive impairment were not included. Research protocol was approved by the local research ethics committee (number 889/12), and all the participants signed an informed consent form prior to their inclusion in the study.

\section{Instruments and measures}

Demographic, anthropometric, and clinical data were obtained by interview and chart review. Diagnosis of asthma was based on previous identification of a characteristic pattern of respiratory symptoms, such as wheezing, dyspnea, chest tightness, or cough, and objective demonstration of variable airflow limitation, according to current recommendations [1]. Asthma
Control Test (ACT) was used to evaluate the level of asthma control. This is a practical and simple instrument widely used for this purpose and has been previously translated and validated for use in Brazil [15]. It is composed of five questions with five possible answers each, individually scored from 1 to 5. Total score may thus range from 5 (worst control) to 25 points (optimal control), and a score $\geq 20$ is considered indicative of well-controlled asthma [16].

Depressive symptoms were assessed by the BrazilianPortuguese language version of the Beck Depression Inventory (BDI) [17]. This instrument consists of 21 items rated on a Likert-type scale, from 0 (neutral) to 3 (maximum intensity). The final score can thus range from 0 to 63 points, corresponding to normal ( 0 to 9 ), mild (10 to 18$)$, moderate (19 to 29), and severe (30 to 63) symptoms [18].

Quality of sleep was assessed by the Brazilian-Portuguese version of the Pittsburgh Sleep Quality Index (PSQI). This questionnaire comprises 19 items that compose seven scoring components, each one related to a specific aspect of sleep: subjective sleep quality, sleep latency, sleep duration, habitual sleep efficiency, sleep disturbances, use of hypnotics or sedative drugs, and daytime dysfunction. The score of each component is added so that the global score can range from 0 to 21 points. Overall global score higher than 5 is considered indicative of poor quality sleep [19].

The degree of daytime sleepiness was assessed by the Epworth Sleepiness Scale (ESS), a questionnaire widely used for this purpose, which has been previously translated and validated for use by Brazilian subjects [20]. It is composed of eight questions that ask for the likelihood of falling asleep in eight hypothetical situations, quantified as 0 (no chance), 1 (small chance), 2 (moderate chance), or 3 (high chance). The final score ranges from 0 to 24 points, and scores $\geq 10$ are considered indicative of excessive daytime sleepiness [21].

\section{Statistical analysis}

Data are expressed as mean, standard deviation (SD), and/or frequency. Chi-squared test was used for analysis of dichotomous variables. The Kolmogorov-Smirnov test was used to assess normality. In between-group comparisons, Student's $t$ test or Mann-Whitney test were used, as appropriate. To measure the association between variables, we used the Pearson correlation coefficient. Multiple regression analysis (stepwise) was used to identify the factors more strongly related to the degree of asthma control. In this analysis, the dependent variable was ACT score; BDI and PSQI were the independents variables, adjusted for the covariates age, body mass index (BMI), and ESS score. The selection of independent variables was done according to their clinical and statistical significance in previous analyses. Two-tailed tests were used throughout the study, with alpha set at $5 \%$ probability $(p<0.05)$. 
Analyses were performed using the Statistic Package for Social Sciences (SPSS) version 20.0 for Windows.

\section{Results}

The patients were aged between 18 and 83 (mean \pm $\mathrm{SD}=50.8 \pm 12.2$ ) years. A combination of inhaled corticosteroids and long-acting beta agonists was used by $118(95.9 \%)$ individuals and systemic corticosteroids by $10(8.1 \%)$. All the subjects reported the use of inhaled short-acting beta agonists on an as-needed basis. Antidepressants were used by 16 $(13.0 \%)$ patients, antihypertensives by $48(39.0 \%)$, protonpump inhibitors by $23(18.7 \%)$, lipid-lowering drugs by 15 $(12.2 \%)$, and oral antidiabetic agents by $7(5.7 \%)$. One subject was a current smoker and 38 (30.9\%) were ex-smokers. Data on asthma control, sleep quality, daytime sleepiness, and depressive symptoms are summarized in Table 1.

The severity of depressive symptoms was classified as mild $(20 \geq$ BDI $>10)$ in $53(43.09 \%)$ cases, moderate $(30 \geq \mathrm{BDI}>20)$ in $28(22.77 \%)$, and severe (BDI $>30)$ in $11(8.94 \%)$. Of the 39 subjects with moderate or severe depressive symptoms, 8 (20.5\%) were on antidepressants. On average, the patients with depressive symptoms, as compared to those without, had poorer control of asthma, worse quality of sleep, and a higher sleepiness score (Fig. 1). Correlation analysis showed that cases with lower BDI, i.e., less $\square \mathrm{BDI}<10 \quad \square \mathrm{BDI} \geq 10$

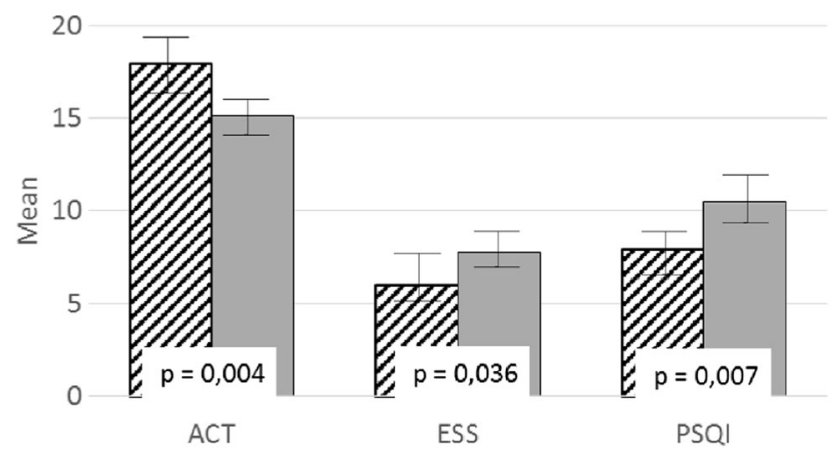

Fig. 1 Women with asthma and depressive symptoms showed lower levels of disease control, poorer sleep quality, and more daytime sleepiness than those without depressive symptoms. ACT Asthma Control Test, ESS Epworth Sleepiness Scale, PSQI Pittsburgh Sleep Quality Index, 95\% CI $95 \%$ confidence interval

depressive symptoms, had higher ACT scores, indicating better asthma control $(R=-0.299 ; p=0.001)$ as well as lower PSQI scores, indicating better quality sleep $(R=0.326$; $p<0.001$ ).

Asthma control was worse in patients with poor quality sleep in comparison to that in those with good quality sleep (Fig. 2). A negative correlation was found between PSQI and ACT scores, suggesting that patients with better quality sleep present higher levels of asthma control $(R=-0.315$; $p<0.001)$. On average, participants with excessive daytime
Table 1 General characteristics, sleep quality, daytime sleepiness, and depressive symptoms in 123 women with asthma, according to the level of disease control

\begin{tabular}{lllll}
\hline & All patients $(N=123)$ & $\begin{array}{l}\text { Poorly controlled } \\
\text { asthma }(N=94)\end{array}$ & $\begin{array}{l}\text { Well-controlled } \\
\text { asthma }(N=29)\end{array}$ & $p$ value* \\
\hline Age (years) & $50.8 \pm 12.2$ & $49.6 \pm 11.6$ & $54.5 \pm 13.6$ & $0.058^{\mathrm{a}}$ \\
BMI $\left(\mathrm{kg} / \mathrm{m}^{2}\right)$ & $28.4 \pm 5.2$ & $28.9 \pm 5.5$ & $26.9 \pm 3.4$ & $0.045^{\mathrm{a}}$ \\
PSQI, global score & $9.9 \pm 4.6$ & $10.6 \pm 4.4$ & $7.4 \pm 4.4$ & $0.001^{\mathrm{b}}$ \\
Poor quality sleep & $99(80.4 \%)$ & $81(86.2 \%)$ & $18(62.1 \%)$ & $0.004^{\mathrm{c}}$ \\
$\quad$ Present & $24(19.6 \%)$ & $13(13.8 \%)$ & $11(37.9 \%)$ & \\
$\quad$ Absent & $7.3 \pm 4.4$ & $7.5 \pm 4.5$ & $6.7 \pm 4.1$ & $0.347^{\mathrm{b}}$ \\
ESS score & $34(27.6 \%)$ & $29(30.9 \%)$ & $5(17.2 \%)$ & $0.152^{\mathrm{c}}$ \\
Hypersomnolence & $89(72.4 \%)$ & $65(69.1 \%)$ & $24(82.8 \%)$ & \\
$\quad \begin{array}{l}\text { Present } \\
\text { Absent }\end{array}$ & $17.0 \pm 8.6$ & $17.7 \pm 8.8$ & $14.8 \pm 7.7$ & $0.079^{\mathrm{b}}$ \\
BDI score & & & \\
Depressive symptoms & $92(74.7 \%)$ & $22(76.6 \%)$ & $20(69.0 \%)$ & $0.408^{\mathrm{c}}$ \\
$\quad \begin{array}{l}\text { Present } \\
\text { Absent }\end{array}$ & $31(25.3 \%)$ & $9(31.0 \%)$ & \\
\hline
\end{tabular}

BMI body mass index, PSQI Pittsburgh Sleep Quality Index, ESS Epworth Sleepiness Scale, BDI Beck Depression Inventory

* $p$ values are for comparisons between controlled and poorly controlled asthma groups

${ }^{\text {a }}$ Student's $t$ test

${ }^{\mathrm{b}}$ Mann-Whitney

${ }^{\mathrm{c}}$ Chi-squared test 


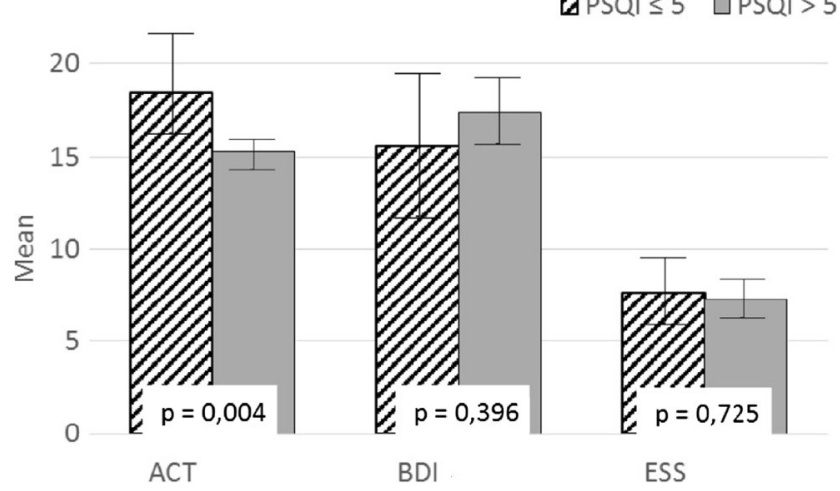

Fig. 2 Women with asthma who presented poor quality sleep exhibited lower level of disease control, relative to those with good quality sleep. ACT Asthma Control Test, BDI Beck Depression Inventory, ESS Epworth Sleepiness Scale, PSQI Pittsburgh Sleep Quality Index, 95\% CI $95 \%$ confidence interval

sleepiness $(\mathrm{ESS} \geq 10)$ had worse levels of asthma control $(p=0.02)$.

Multiple regression analysis showed that depressive symptoms, as measured by the BDI, and subjective sleep quality, as measured by PSQI, were independent predictors of the level of asthma control (Table 2).

\section{Discussion}

This study shows that asthma control in women is independently associated with depressive symptoms and quality of sleep. Less than a quarter of the study participants exhibited, at least, partially controlled asthma, as assessed by the ACT. In a recent study, Al-Zahrani et al. also using the ACT reported an overall rate of uncontrolled disease of $39.8 \%$ in 400 patients from a primary care center. Female participants, however, presented a rate of uncontrolled asthma of $78.6 \%$, i.e., close to the present study and more than four times higher than men [22]. Mintz et al. in a cross-sectional evaluation of 2238 adults in primary care units reported a general frequency of $58 \%$ of uncontrolled asthma, also measured by ACT. But when asthma was the main reason for seeking medical assistance, that rate rose to $72 \%$, slightly lower than that in the present study. Interestingly, according to Mintz et al., $48 \%$ of the patients who attended the health center for medical problems other than asthma had uncontrolled disease [23].

A European multinational study found poorly controlled disease in more than $50 \%$ of patients treated for asthma and more often in women, assessed by ACT. There was substantial variation in the rate of asthma control among various countries, which was attributed to differences in the level of organization of health care systems [24]. In Brazil, Vieira et al. investigated 78 patients with previous diagnosis of moderate to severe asthma from an outpatient clinic at a university hospital, and found that about $60 \%$ of the subjects had uncontrolled asthma, as assessed by ACT, with no difference between genders [5]. This set of results shows clearly that a major proportion of asthma patients suffer from inadequate disease control, particularly women, despite significant advances in the knowledge of asthma pathophysiology and pharmacotherapy, thus highlighting the need for a better assessment and control of individual risk factors [25].

Depressive symptoms were observed in most participants of this study. Previously, depression rates consistently higher than those observed in the general population have been reported in patients with asthma [4]. Moreover, asthma patients show depressive symptoms more often than patients with other chronic diseases, which also significantly interfere with the activities of daily living [26, 27]. In a cohort of 439 adults with asthma, mostly of female gender, Katz et al. observed a depression rate twice as high as for the general population. Low perception of asthma control was associated with the presence of depression in that study [28]. Depression was reported in $25 \%$ of the participants of a retrospective cohort study, involving 1812 patients with moderate and severe persistent asthma [29]. Recently, Bruner et al. conducted a longitudinal study with a 20 -year follow-up, involving 3614 adults, initially free from asthma, classified according to the presence of depressive symptoms, and found that depression is a risk factor for the incidence of asthma. By contrast, there was no increased incidence of depression in 3016 adults with asthma, also included in the same study [30].
Table 2 Multiple regression analysis of Asthma Control Test (ACT) score and other characteristics of 123 women with asthma

\begin{tabular}{llllll}
\hline Predictors & Coefficients & SE & Student's $t$ test & $p$ value & $95 \%$ CI \\
\hline Constant & 19.239 & 3.29 & 0.83 & 0.00 & $12.68-25.78$ \\
BDI & -0.119 & 0.054 & -2.19 & 0.03 & $-0.227-0.011$ \\
PSQI & -0.255 & 0.105 & -2.43 & 0.01 & $-0.46-0.04$ \\
\hline
\end{tabular}

95\%CI $95 \%$ confidence interval, BDI Beck Depression Inventory, PSQI Pittsburgh Sleep Quality Index, ACT Asthma Control Test, SE Standard Error 
In this study, there was an association between depressive symptoms and level of asthma control. Previously, Di Marco et al. reported an association between depression and inadequate asthma control, measured by ACT. Those investigators suggested that an increase in awareness of asthma symptoms caused by depression could be negatively affecting the level of control, as perceived by the patient [31]. However, there are many additional factors that might contribute to the relationship between depressive symptoms and poor asthma control, including low adherence to drug therapy [32] and increased use of emergency services for asthma patients with depressive symptoms, compared to individuals who do not present these symptoms [33]. The high frequency of depressive symptoms in asthma, confirmed by the present study, assumes even greater relevance in view of the fact that psychiatric comorbidities, although common in chronic respiratory diseases, still remain largely undiagnosed and untreated. This is also evident from our finding that only one fifth of the patients with moderate or severe depressive symptoms were receiving specific treatment.

Poor sleep quality was observed in the majority of the participants of this study, particularly in those with depressive symptoms or poorly controlled disease. Excessive daytime sleepiness was present in just under a third of our cases. Impaired sleep and its negative daytime consequences have been previously reported in asthma, even in patients with mild and relatively stable disease [7-12]. Insomnia-related symptoms have been described in almost half of the subjects with asthma in a large population-based survey, with higher frequencies being found in females and asthmatics with nocturnal symptoms [34]. Obstructive sleep apnea (OSA), a common cause of disturbed sleep, particularly in middleaged adults, has been frequently reported in asthma [35] and may also have contributed to worsen sleep quality in our subjects.

One of the main findings of the present study is that asthma control is independently related to subjective sleep quality, regardless of the presence of depressive symptoms. Previously, the relationship between asthma control and quality of sleep was examined in a very limited number of studies, and the potential confounding effect of depression has not been accounted for [7, 9, 10]. Luyster et al. investigated the effects of gastroesophageal reflux disease, allergic rhinitis, and obstructive sleep apnea, but not depressive symptoms, on asthma control, and observed an association between low level of asthma control and poor sleep quality. In the same study, it was found that patients without nocturnal symptoms of asthma almost always presented poor sleep quality, indicating that the high frequency of sleep problems in asthma cannot be secondary only to the presence of nocturnal symptoms [36]. Additionally, the possibility of a mutual relationship between asthma control and quality of sleep should be considered. In fact, negative effects of insufficient sleep on pulmonary function were previously described in patients with chronic obstructive pulmonary disease [37]. In experimental animals, sleep deprivation can exacerbate acute lung inflammation, an effect that can be attenuated by melatonin, which has a powerful antioxidant action [38]. Interestingly, nocturnal melatonin administration can reportedly improve the quality of sleep in women with mild to moderate stable asthma [12].

The present study has several limitations. First, as no male patients were included, these results cannot be immediately extrapolated to the entire asthmatic population. On the other hand, because of well-recognized effects of gender on clinical manifestations and disease control in asthma [2], recruiting only female subjects allowed for the exclusion of a potentially relevant confounding factor. In this study, quality of sleep was evaluated subjectively by the PSQI, an instrument widely used for this purpose. Previous reports indicate that subjective criteria are superior to polysomnography in identifying individuals with insomnia, and laboratory records add little relevant information to confirm or exclude this condition [39]. Finally, because of its cross-sectional design, causality cannot be inferred from the relationships described.

In conclusion, depressive symptoms are present in the majority of female outpatients with asthma and are associated with impaired quality of sleep and inadequate disease control. These findings, added to the observation that in asthmatic subjects, depressive symptoms remain largely untreated, reinforce the need to evaluate these patients more routinely for the presence of depression and possibly indicate that adequate measures to treat this problem could have a positive effect on asthma control. Our demonstration of an independent association between poor quality sleep and inadequate asthma control, regardless of depressive symptoms, is relevant and suggests that simple measures to promote healthy sleep behavior and adequate sleep hygiene could be beneficial in this clinical context. New prospective studies involving asthmatic patients of both genders are needed to further characterize these relationships and to evaluate the efficacy of the proposed interventions.

Acknowledgments Thisciane F. Pinto and Francineide Lima Campos were the recipients of scholarships from the Coordenação de Aperfeiçoamento de Pessoal de Nível Superior (CAPES), Brazil, and Francisco Girleudo Coutinho da Silva was the recipient of a scholarship from the Fundação Cearense de Apoio ao Desenvolvimento Científico e Tecnológico (FUNCAP). The authors wish to thank Mr. Antonio Brazil Viana Júnior for the technical assistance. 


\section{Compliance with ethical standards}

Funding No funding was received for this research.

Conflict of interest The authors declare that they have no competing interests.

Ethical approval All procedures performed in studies involving human participants were in accordance with the ethical standards of the institutional research committee and with the 1964 Helsinki declaration and its later amendments.

Informed consent Informed consent was obtained from all the individual participants included in the study.

\section{References}

1. Global Initiative for Asthma (GINA) (2015) Pocket guide for asthma management and prevention for adults and children older than 5 years. http://ginasthma.org/wp-content/uploads/2016/01/GINA Pocket 2015.pdf. Accessed 18 May 2016

2. McCallister JW, Holbrook JT, Wei CY, Parsons JP, Benninger CG, Dixon AE, Gerald LB, Mastronarde JG, American Lung Association Asthma Clinical Research Centers (2013) Sex differences in asthma symptom profiles and control in the American Lung Asthma Clinical Research Centers. Resp Med 107:14911500. doi:10.1016/j.rmed.2013.07.024

3. Sociedade Brasileira de Pneumologia e Tisiologia (2012) Diretrizes da Sociedade Brasileira de Pneumologia e Tisiologia para o Manejo da Asma. J Bras Pneumol 38(Suppl I):1-46

4. Di Marco F, Santus P, Centanni S (2011) Anxiety and depression in asthma. Curr Opin Pulm Med 17:39-44. doi:10.1097/mcp.0b013 e328341005f

5. Vieira AA, Santoro IL, Dracoulakis S, Caetano LB, Fernandes AL (2011) Anxiety and depression in asthma patients: impact on asthma control. J Bras Pneumol 37:13-18. doi:10.1590/S180637132011000100004

6. Litinski M, Scheer FA, Shea SA (2009) Influence of the circadian system on disease severity. Sleep Medicine Clinics 4:143-163. doi:10.1016/j.jsmc.2009.02.005

7. Braido F, Baiardini I, Ghiglione V, Fassio O, Bordo A, Cauglia S et al (2009) Sleep disturbances and asthma control: a real life study. Asian Pac J Allergy Immunol 27(1):27-33

8. Janson C, De Backer W, Gislason T, Plaschke P, Björnsson E, Hetta $\mathrm{J}$ et al (1996) Increased prevalence of sleep disturbances and daytimes sleepiness in subjects with bronchial asthma: a population study of young adults in three European countries. Eur Respir J 9: 2132-2138. doi:10.1183/09031936.96.09102132

9. Krouse HJ, Yarandi H, McIntosh J, Cowen C, Selim V (2008) Assessing sleep quality and daytime wakefulness in asthma using wrist actigraphy. J Asthma 45:389-395. doi:10.1080/02770900801971800

10. Mastronarde JG, Wise RA, Shade DM, Olopade CO, Scharf SM, American Lung Association Asthma Clinical Research Centers (2008) Sleep quality in asthma: results of a large prospective clinical trial. J Asthma 45:183-189. doi:10.1080/02770900801890224

11. Fitzpatrick MF, Engleman H, Whyte KF, Deary IJ, Shapiro CM, Douglas NJ (1991) Morbidity in nocturnal asthma: sleep quality and daytime cognitive performance. Thorax 46:569-573. doi:10.1136/thx.46.8.569
12. Campos FL, da Silva-Júnior FP, de Bruin VM, de Bruin PF (2004) Melatonin improves sleep in asthma: a randomized, double-blind, placebo-controlled study. Am J Resp Crit Care Med 170:947-951. doi:10.1164/rccm.200404-488OC

13. Buysse DJ, Angst J, Gamma A, Ajdacic V, Eich D, Rössler W (2008) Prevalence, course, and comorbidity of insomnia and depression in young adults. Sleep 31:473-480

14. Franzen PL, Buysse DJ, Rabinovitz M, Pollock BG, Lotrich FE (2010) Poor sleep quality predicts onset of either major depression or subsyndromal depression with irritability during interferon-alpha treatment. Psychiat Res 177:240-245. doi:10.1016/j. psychres.2009.02.011

15. Roxo JP, Ponte EV, Ramos DC, Pimentel L, D'Oliveira J, Cruz AA (2010) Portuguese-language version of the Asthma Control Test. J Bras Pneumol 36:159-166. doi:10.1590/s180637132010000200002

16. Schatz M, Sorkness CA, Li JT, Marcus P, Murray JJ, Nathan RA et al (2006) Asthma Control Test: reliability, validity and responsiveness in patients not previously followed by asthma specialists. J Allergy Clin Immunol 117:549-556. doi:10.1016/j. jaci.2006.01.011

17. Gorenstein C, Andrade L (1996) Validation of a Portuguese version of the Beck Depression Inventory in Brazilian subjects. Braz J Med Biol Res 29:453-457. doi:10.1590/s0100-879x2005000300011

18. Beck AT, Ward CH, Mendelson M, Mock J, Erbaugh J (1961) An inventory for measuring depression. Archives General Psychiatry 4: 561-571. doi:10.1001/archpsyc.1961.01710120031004

19. Bertolazi AN, Fagondes SC, Hoff LS, Dartora EG, Miozzo IC, de Barba ME et al (2011) Validation of the Brazilian Portuguese version of the Pittsburgh Sleep Quality Index. Sleep Med 12:70-75. doi:10.1016/j.sleep.2010.04.020

20. Bertolazi AN, Fagondes SC, Hoff LS, Pedro VD, Barreto SS, Johns MW (2009) Portuguese-language version of the Epworth Sleepiness Scale: validation for use in Brazil. J Bras Pneumol 35: 877-883. doi:10.1590/s1806-37132009000900009

21. Johns MW (1991) A new method for measuring daytime sleepiness: the Epworth sleepiness scale. Sleep 14:540-545

22. Al-Zahrani JM, Ahmad A, Abdullah AH, Khan AM, Al-Bader B, Baharoon $S$ et al (2015) Factors associated with poor asthma control in the outpatient clinic setting. Ann Thorac Med 10:100-104. doi:10.4103/1817-1737.152450

23. Mintz M, Gilsenan AW, Bui CL, Ziemiecki R, Stanford RH, Lincourt W et al (2009) Assessment of asthma control in primary care. Curr Med Res Opin 25:2523-2531. doi:10.1185/03007990903218655

24. Demoly P, Annunziata K, Gubba E, Adamek L (2012) Repeated crosssectional survey of patient-reported asthma control in Europe in the past 5 years. Eur Respir Rev 21:66-74. doi:10.1183/09059180.00008111

25. Wechsler M (2014) Getting control of uncontrolled asthma. Am J Med 127:1049-1059. doi:10.1016/j.amjmed.2014.05.006

26. Centanni S, Di Marco F, Castagna F, Boveri B, Casanova F, Piazzini A (2000) Psychological issues in the treatment of asthmatic patients. Resp Med 94:742-749. doi:10.1053/rmed.1999.0766

27. Lyketsos CG, Lyketsos GC, Richardson SG, Beis A (1987) Dysthymic states and depressive syndromes in physical conditions of presumably psychogenic origin. Acta Psychiat Scand 76(5): 529-534. doi:10.1111/j.1600-0447.1987.tb02914.x

28. Katz PP, Morris A, Blanc PD (2010) Depressive symptoms among adults with asthma from a longitudinal observational cohort. Primary Care Respiratory Journal 19:223-230. doi:10.4104/pcrj.2010.00012

29. Haselkorn T, Chen H, Miller DP, Fish JE, Peters SP, Weiss S et al (2010) Asthma control and activity limitations: insights from the Real-world Evaluation of Asthma Control and Treatment (REACT) study. Annals of allergy, asthma \& immunology 104:471-477. doi:10.1016/j.anai.2010.04.006 
30. Brunner WM, Schreiner PJ, Sood A, Jacobs DR Jr (2014) Depression and risk of incident asthma in adults. The CARDIA study. Am J Resp Crit Care Med 189:1044-1051. doi:10.1164/rccm.201307-1349oc

31. Di Marco F, Verga M, Santus P, Giovannelli F, Busatto P, Neri M, Girbino G, Bonini S, Centanni S (2010) Close correlation between anxiety, depression, and asthma control. Resp Med 104(1):22-28. doi:10.1016/j.rmed.2009.08.005

32. Baiardini I, Braido F, Giardini A, Majani G, Cacciola C, Rogaku A, Scordamaglia A, Canonica GW (2006) Adherence to treatment: assessment of an unmet need in asthma. J Invest Allerg Clin Immunol 16(4):218-223

33. Mancuso CA, Rincon M, Mcculloch CE, Charlson ME (2001) Selfefficacy depressive symptoms, and patients expectations predict outcomes in asthma. Med Care 39:1326-1338. doi:10.1097/00005650200112000-00008

34. Sundbom F, Lindberg E, Bejerg A, Fosberg B, Franklin K, Gunnbjörnsdottir M et al (2013) Asthma symptoms and nasal congestion as independent risk factors for insomnia in a general population: results from the GA 2 Len survey. Allergy 68:213219. doi:10.111/all.12079

35. Alkhalil M, Schulman E, Getsy J (2009) Obstructive sleep apnea syndrome and asthma: what are the links? J Clin Sleep Med 5:71-78

36. Luyster FS, Teodorescu M, Bleecker E, Busse W, Calhoun W, Castro M, Chung KF, Erzurum S, Israel E, Strollo PJ, Wenzel SE (2012) Sleep quality and asthma control and quality of life in non-severe and severe asthma. Sleep Breath 16:1129-1137. doi:10.1007/s11325-011-0616-8

37. Phillips BA, Cooper KR, Burke TV (1987) The effect of sleep loss on breathing in chronic obstructive pulmonary disease. Chest 91: 29-32. doi:10.1378/chest.91.1.29

38. Kim JY, Lee YD, Kim BJ, Kim SP, Kim DH, Jo KJ, Lee SK, Lee KH, Baik HW (2012) Melatonin improves inflammatory cytokine profiles in lung inflammation associated with sleep deprivation. Mol Med Rep 5:1281-1284. doi:10.3892/mmr.2012.814

39. Vgontzas AN, Bixler EO, Kales A, Manfredi RL, Tyson K (1994) Validity and clinical utility of sleep laboratory criteria for insomnia. Int J Neurosci 77:11-21. doi:10.3109/00207459408986015 